\title{
Trabajando en equipo: múltiples perspectivas acerca del trabajo cooperativo y colaborativo
}

\section{Working in teams: multiple perspectives on collaborative and cooperative work}

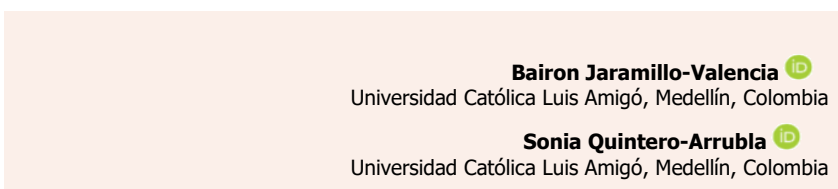

\section{Resumen}

Objetivo: Desarrollar un estado de arte para comprender acerca de los componentes que rodean las prácticas del trabajo en equipo, al igual que el aprendizaje colaborativo y cooperativo; modalidades que se desprenden del primero mencionado. Método: El método utilizado fue el reconocido como Revisión Documental, a través de una perspectiva cualitativa de investigación. Asimismo, se llevó a cabo una búsqueda exclusiva de revistas indexadas, a través de los nombrados operadores Booleanos AND, OR y NOT. A su vez, las categorías base fueron 'Aprendizaje Colaborativo' y 'Aprendizaje Cooperativo', cuyos procesos de análisis documental se desarrollaron a través de la lectura filtrada en criterio y contenido. Resultados: Se logró dar exactitud a los respectos conceptuales y procedimentales de estos procederes grupales; a su vez, toda la información encontrada posibilitó una mejor comprensión de la investigación base ya finiquitada (Prácticas pedagógicas innovadoras implementadas por los docentes, para favorecer el trabajo colaborativo en el aprendizaje con estudiantes de la facultad de educación), desarrollada en Medellín, Colombia. Discusión y Conclusiones: Se concluye que los conceptos de colaboración y cooperación se diferencian marcadamente en los procedimientos de trabajo y las interacciones entre los integrantes de grupo; de modo similar, se debe reconocer que existe similitud de ambos, en cuanto a productos se refiere.

Palabras clave: Aprendizaje, cooperación, estudiante, grupo, trabajo.
Open Access:

ISSN: $0124-2121$ E-ISSN: $2665-2420$

ARTÍCULO RESULTADO DE REVISIÓN BIBLIOGRÁFICA Copyright $\odot$
By Educación y Humanismo

Editor: Dhayana Fernández Matos

Correspondencia: bairon.jaramillova@amigo.ed u.co

Recibido: 02-01-2021 Aceptado: 08-05-2021 En línea desde: 22-09-2021

\begin{abstract}
Objective: To develop a state of the art to understand the components that surround teamwork practices, as well as collaborative and cooperative learning; modalities that are derived from the first mentioned. Method: The method used was that recognized as Documentary Review, through a qualitative research perspective. Likewise, an exclusive search of indexed journals was carried out, through the so-called Boolean operators AND, OR and NOT. In turn, the base categories were 'Collaborative Learning' and 'Cooperative Learning', whose documentary analysis processes were developed through filtered reading in criteria and content. Results: It was possible to give accuracy to the conceptual and procedural aspects of these group procedures; in turn, all the information found made possible a better understanding of the base research already finalized (Innovative pedagogical practices implemented by teachers, to favor collaborative work in learning with students of the faculty of education), developed in Medellin, Colombia. Discussion and Conclusions: It is concluded that the concepts of collaboration and cooperation differ markedly in the work procedures and interactions among group members; similarly, it should be recognized that there is similarity of both, as far as products are concerned.
\end{abstract}

Keywords: Learning, cooperation, student, group, work.

Cómo citar este artículo (APA): Jaramillo-Valencia, B. y Quintero-Arrubla, S. (2021). Trabajando en equipo: múltiples perspectivas acerca del trabajo cooperativo y colaborativo. Educación y Humanismo, 23(41), 205-233. https://doi.org/10.17081/eduhum.23.41.4188 


\section{Introducción}

El trabajo en equipo es una actividad que se caracteriza por tener una serie de tareas llevadas a cabo por un grupo de personas, las cuales buscan congruentemente un fin común. Posiblemente la definición anterior —un tanto básica de hecho- representa una dinámica que los seres humanos llevan a cabo de forma intermitente durante toda su existencia; no obstante, el trabajo en equipo es una cuestión que va más allá de la simple labor colectiva desarrollada por un conjunto de individuos.

El presente texto tiene como propósito la caracterización -a través de un exhaustivo y riguroso estado de arte- de los elementos que rodean las acciones del trabajo en equipo, el trabajo cooperativo y el trabajo colaborativo; estos dos últimos subyacentes al primero.

Se realiza esta empresa, además de conocer a profundidad las diferencias y similitudes conceptuales de los vocablos a trabajar, con el fin de nutrir teóricamente el marco conceptual de una investigación ya finiquitada, denominada Prácticas pedagógicas innovadoras implementadas por los docentes, para favorecer el trabajo colaborativo en el aprendizaje con estudiantes de la facultad de educación, y desarrollada bajo el patrocinio de la Universidad Católica Luis Amigó durante los períodos 2019-1 y 2019-2.

El planteamiento del problema en este estudio se da a partir de la falta de exactitud epistemológica, y por consiguiente procedimental, en los docentes de la facultad de educación de la Universidad Católica Luis Amigó (participantes en este estudio), los cuales delegaban trabajos a sus estudiantes, desde la "cooperación" y/o "colaboración", sin tener una precisión sobre lo que conllevan trabajar bajo estos dos procederes:

Aunque para alguna parte de los educadores y estudiosos de las ciencias educativas, los términos cooperativo y colaborativo son similares y se les otorga cualidades semejantes, se suele tener un dilema relacionado con que si sus alcances son equivalentes respecto del aprendizaje grupal (Zárate, 2016, p. 7).

La razón por la cual se decide realizar un proceso de escritura acerca del trabajo en equipo y sus dos marcadas connotaciones (cooperar y colaborar), se da con el fin de conocer cómo estos docentes (unidades de análisis) llevaban a cabo estas dinámicas en sus labores académicas con los estudiantes universitarios; y luego que los investigadores aplicaran técnicas, recolectaran y analizaran resultados, se pudiese entonces ejecutar un plan de acción que les permitiese a los maestros cualificar su quehacer: "Un plan de acción es una herramienta muy potente para alinear premisas y avanzar en una misma dirección. Este objetivo se buscaba desde el diseño mismo del plan" (Martínez, Gmelch y Xarles, 2019, p. 7). 
Esto posibilitó que estos dinamizaran y enfocaran certeramente la enseñanza hacia los estudiantes universitarios de esta institución educativa, comprendiendo que el trabajo entre personas es una actividad sumamente fundamental en diferentes labores y sectores de la vida; más aún, en lo concerniente a los procesos de enseñanza y aprendizaje. Sobre la necesidad de tener claridad en aspectos metodológicos para el quehacer docente, Rivarossa y Bruccini (2017) apuntan que:

El posicionamiento epistemológico de los docentes formadores, genera una relación con el conocimiento desde paradigmas socio-crítico y de la complejidad, se habilitarían otras relaciones con el saber, propiciando no sólo prácticas reflexivas sino también una postura epistémica que permita generar propuestas desde interrogantes y no desde certezas incuestionables (p. 4)

Cuando los sujetos que hacen parte de un conjunto deciden realizar una serie de tareas coordinadas, baladímente se le puede llamar a esto "trabajo en grupo", y como es de igual forma una acción connatural del día a día, puede suponer que es innecesaria una revisión documental -y su respectivo análisis - para establecer firmemente lo que representa. En este sentido, Panitz (2001) establece que el trabajo en equipo permite la realización de actividades que se llevan a cabo conjuntamente, más allá del compartir un mismo espacio físico. De igual modo, es preciso apuntar que no todo trabajo grupal conlleva a un trabajo en equipo; asunto que se ahondará más adelante en la sección de desarrollo conceptual.

No obstante, el hecho de llegar a acuerdos con alguien para lograr el éxito en un producto, conlleva a algo más que la habitual delegación de tareas individuales; y pese a lo que puedan pensar algunos sobre la relevancia que tiene un producto final, subvalorando el proceso que se tuvo para llegar a este, al final la realidad objetual y simbólica dan la razón a ambos, pues dichas relaciones — de igual forma- dan fe de las prácticas idóneas en un espacio y tiempo determinado.

En este sentido, se puede llegar a un producto conjunto a través de la colaboración, definida como la capacidad de realizar actividades en las cuales todos los miembros comparten, conocen y se responsabilizan por el producto en su totalidad (Collazos y Mendoza, 2006). A lo que Lillo, Muñoz y Butter (2020) agregan, determinando que la colaboración requiere de una interdependencia constante en el proceso de trabajo en equipo, al igual que la contribución de cada quien a través de una sostenida interacción en el trabajo.

Por otro lado, no de forma inexorablemente antagónica pero si diferencial, la cooperación -y más que todo en el trabajo entre profesionales en formación- conlleva a una responsabilidad de cada individuo del grupo para con la tarea final que es responsabilidad del colectivo; interacción que no se acentúa en los roles naturales de los miembros del equipo que trabaja (Rus, Martínez, Frutos y Moreno, 2019). A lo que Yorg y Zarza (2020) agregan, determinando que el control procedimental de la cooperación es dirigida por una 
figura de autoridad ajena al colectivo; ya sea un docente, profesor o tutor, que muestre a los miembros el abecé de las actividades para lograr con éxito una producción final.

Por tal motivo, y con base a lo anteriormente establecido, al detectar las formas en que las unidades de análisis (en la investigación fundante) delegan el trabajaron a sus estudiantes, posibilitó la ejecución de un plan de acción por parte de los investigadores, lo cual permitió cualificar la labor docente en el contexto donde se llevó a cabo este estudio.

\section{Método}

La metodología de este proceso investigativo está fundamentada bajo la denominada Revisión Documental: "una revisión documental es una técnica que depende fundamentalmente de la información que se obtiene sobre un determinado tema, este material al que se acude como fuente de referencia aporta investigaciones o dan testimonio de una realidad" (Delgado y Herreño, 2018, p. 9). Con base a lo establecido bajo este referente, este actuar investigativo ofrece la posibilidad de enfocar la búsqueda, recolección y sistematización de la información hacia un horizonte temático determinado. Por otra parte, se establece una perspectiva cualitativa, puesto que se busca -además de datarcomprender eso que se está registrando; en este caso, los fenómenos del trabajo cooperativo y colaborativo:

El enfoque cualitativo permite profundizar con mayor amplitud la práctica, el fenómeno educativo y contribuye a la concienciación social. Debido a que por un lado, posibilita analizar y explicar la comprensión de la complejidad, el detalle, el contexto y la interacción social (Daza, 2018, pp. 105-106)

Por otra parte, en lo concerniente al proceso de búsqueda y criterios de selección en los textos a trabajar, se puede declarar que durante el proceso de búsqueda de información ciertamente necesario para el desarrollo de esta revisión de la literatura- se establecieron ciertos parámetros para seleccionar las fuentes apropiadas, con el fin de realizar el respectivo desarrollo escritural; revistas indexadas encontradas en bases de datos como: Scopus, Web of Science (WOS), EBSCO, Scielo, DOAJ, Dialnet, Ulrich 's y Carhus +, sirvieron de recipiente académico debido su inherente calidad en temáticas y rigurosidad en cuanto a metodología se refiere. Consecuentemente, los contenidos desarrollados a lo largo de este texto, se encontraban indexados en Quartile (Q)1, y mayormente en Q2, Q3 y Q4, puesto que la temática, al parecer, se percibía más vinculada a los estudios sociales; consistencia que la situaba en estos cuartiles; y a su vez, la hacía análoga en cuanto a su metodología, ya que -en el mayor de los casos - las bibliografías denotaban estudios cualitativos, de cortes tanto descriptivos como explicativos.

Por otro lado -en cuanto a los criterios de fiabilidad, validez y rechazo - se excluyeron en la búsqueda a través de las bases de datos, artículos cuyos resultados incorporaran palabras tales como 'tecnología', 'deporte', 'deportes extremos' y 'supervivencia', puesto que 
dichas bibliografías estaban más abocadas a lo tocante en "equipos tecnológicos", "equipos de supervivencia" y "equipamiento de artículos en general", más no de trabajo en equipo de colectivos humanos. Otro criterio de variabilidad y rechazo en la búsqueda de textos académicos, fue la no utilización de bases de datos que incluían artículos no indexados, de divulgación, o de indexación distinta a Q1, Q2, Q3 o Q4, los cuales no fuesen equivalentes a la categorización por cuartiles y con bajo índice de impacto. Es importante resaltar que en este estado de arte, la revista que más registró artículos publicados sobre estos tópicos fue Formación Universitaria, dirigida desde Chile, con una cantidad de 6 en total, seguida de Anales de Psicología de España con 5, Revista Complutense de Educación de España con 5, REDIE: Revista Electrónica de Investigación Educativa de México con 3, Educación Médica de España con 3 y, finalmente, RISTI-Revista Ibérica de Sistemas e Tecnologias de Informação de Portugal con 2, al igual que Estudios pedagógicos (Valdivia) de Chile y Educación y Humanismo de Colombia. A su vez, estos resultados dieron cuenta de diferentes perspectivas sobre los procesos grupales, y las dinámicas de trabajo cooperativo y colaborativo.

Como se ha denotado anteriormente, este texto busca exponer las formas y definiciones del trabajo en equipo, a través de conceptos como 'Trabajo Colaborativo' y 'Trabajo Cooperativo;; del mismo modo, esta búsqueda se realizó a través de los siguientes operadores booleanos, registrados en búsquedas, única y exclusivamente, de contenidos relacionados en revistas indexadas. Sobre esta metodología de pesquisa bibliográfica, González, Tejedor y Pinzón (2019) detallan lo siguiente: "Operadores lógicos: OR, AND, NOT: Los operadores lógicos o booleanos son aquellos términos y símbolos que se utilizan en el proceso de búsqueda de información, para elaborar estrategias de búsqueda más eficientes" (p. 127). A continuación, se presentan las combinaciones utilizadas - a través de los operadores como herramienta investigativa - en la búsqueda de los conceptos requeridos para el desarrollo temático:

- (TITTLE-ABS-KEY (trabajo en equipo) AND TITTLE-ABS-KEY (aprendizaje colaborativo))

- (TITLE-ABS-KEY (trabajo en equipo) AND TITLE-ABS-KEY (trabajo en colaboración))

- (TITLE-ABS-KEY (trabajo en equipo) AND TITLE-ABS-KEY (colaborar))

- (TITLE-ABS-KEY (trabajo en equipo) AND TITLE-ABS-KEY (aprendizaje cooperativo))

- (TITLE-ABS-KEY (trabajo en equipo) AND TITLE-ABS-KEY (trabajo en cooperación))

- (TITLE-ABS-KEY (trabajo en equipo) AND TITLE-ABS-KEY (cooperar))

- (TITLE-ABS-KEY (trabajo colaborativo) AND TITLE-ABS-KEY (grupo de trabajo)) 
- (TITLE-ABS-KEY (trabajo colaborativo) AND TITLE-ABS-KEY (trabajar en equipo))

- (TITLE-ABS-KEY (trabajo colaborativo) AND TITLE-ABS-KEY (equipo))

- (TITLE-ABS-KEY (trabajo cooperativo) AND TITLE-ABS-KEY (grupo de trabajo))

- (TITLE-ABS-KEY (trabajo cooperativo) AND TITLE-ABS-KEY (trabajar en equipo))

\section{- (TITLE-ABS-KEY (trabajo cooperativo) AND TITLE-ABS-KEY (equipo))}

De acuerdo con las búsquedas en los descriptores anteriores, una serie de preguntas fueron las fundantes para ejecutar dichas pesquisas; asimismo, la construcción y selección de estas, fue producto de la significación conceptual (qué-cuáles) y procedimental (cómo), ambas de primer y segundo nivel, con la finalidad de analizar los procesos grupales desde lo connotativo y denotativo de cada concepto. Posteriormente, a lo largo del texto se percibirá cómo estos cuestionamientos fueron respondidos con base a lo encontrado en la literatura.

Por otro lado, en lo concerniente a los criterios de búsqueda, se menciona nuevamente que se hizo a través de la selección de revistas indexadas, provenientes de bases de datos como: Scopus, Web of Science (WOS), EBSCO, Scielo, DOAJ, Dialnet, Ulrich's y Carhus +. Los textos seleccionados para la escritura de este artículo, provenientes de estos alojamientos de contenido científico, se encontraron indexados desde Q1 hasta Q4, todos con temáticas relacionadas al trabajo en equipo, el aprendizaje cooperativo y colaborativo. Sobre los criterios de fiabilidad, validez y rechazo, se excluyeron de la búsqueda, vocablos como 'tecnología', 'deporte', 'deportes extremos' y 'supervivencia', ya que los resultados relacionados estaban más abocados a equipos pero de tecnología, equipos o equipamientos de supervivencia y equipamiento de artículos en general, todo lo anterior al margen del trabajo en equipo de colectivos humanos. A continuación, las preguntas formuladas que guiaron la escritura de este texto:

Q1. ¿Qué es trabajo en equipo?

Q2. ¿Cómo se lleva a cabo el trabajo en equipo y qué elementos se tienen en cuenta?

Q3. ¿Cuáles son los beneficios de trabajar en equipo?

Q4. ¿Cómo se entiende la cooperación?

Q5. ¿Cuáles son los elementos que permiten llevar a cabo un aprendizaje cooperativo?

Q6. ¿Qué favorece el hecho de trabajar cooperativamente?

Q7. ¿Qué es lo que se conoce por aprendizaje colaborativo?

Q8. ¿Cómo se desarrollan las dinámicas colaborativas? 
Q9. ¿Cuáles son los elementos que reivindica el hecho de trabajar colaborativamente?

\section{Tabla 1.}

Organizador comparativo de clasificación

\begin{tabular}{|c|c|}
\hline \multicolumn{2}{|c|}{ Conceptos que pueden generar confusión semántico-procedimental } \\
\hline ¿Qué es trabajo en equipo? & \multirow{3}{*}{$\begin{array}{l}\text { El trajo en grupo no conlleva necesariamente a } \\
\text { trabajo en equipo }\end{array}$} \\
\hline $\begin{array}{l}\text { ¿Cómo se lleva a cabo el trabajo en equipo y qué } \\
\text { elementos se tienen en cuenta? }\end{array}$ & \\
\hline ¿Cuáles son los beneficios de trabajar en equipo? & \\
\hline ¿Cómo se entiende la cooperación? & \multirow{3}{*}{$\begin{array}{l}\text { La cooperación centra su procedimiento en una } \\
\text { figura de autoridad, la cual define los roles y } \\
\text { actuares de los miembros del grupo }\end{array}$} \\
\hline $\begin{array}{l}\text { ¿Cuáles son los elementos que permiten llevar a } \\
\text { cabo un aprendizaje cooperativo? }\end{array}$ & \\
\hline $\begin{array}{lcccc}\begin{array}{l}\text { ¿Qué favorece } \\
\text { cooperativamente? }\end{array} & \text { el hecho de trabajar } \\
\end{array}$ & \\
\hline $\begin{array}{l}\text { ¿Qué es lo que se conoce por aprendizaje } \\
\text { colaborativo? }\end{array}$ & \multirow{3}{*}{$\begin{array}{c}\text { Cada sujeto del equipo está al tanto de las } \\
\text { actividades de los demás y sus relaciones se } \\
\text { gestan de forma espontánea }\end{array}$} \\
\hline ¿Cómo se desarrollan las dinámicas colaborativas? & \\
\hline $\begin{array}{l}\text { ¿Cuáles son los elementos que reivindica el hecho } \\
\text { de trabajar colaborativamente? }\end{array}$ & \\
\hline
\end{tabular}

Fuente: Elaboración propia (2020)

\section{Resultados y Discusión}

\section{Desarrollo y discusión:}

En esta sección, se organizarán los datos a través de una combinación de resultados, con el fin de presentar las percepciones de diferentes estudios acerca de los aspectos determinantes a dar respuesta a las preguntas guía de este artículo de revisión; por lo tanto, se comenzará a hacer recorrido crítico-conceptual sobre lo siguiente:

\section{El Trabajo Equipo y sus Implicaciones}

Q1. ¿Qué es trabajo en equipo?

Para comenzar, se trae a colación una definición establecida por Sepúlveda (2018):

Trabajo en equipo: Demuestra integración y colaboración de forma activa en la consecución de objetivos comunes con otras personas, áreas y organizaciones. El trabajo en equipo implica que los individuos desarrollan actitudes de simpatía y empatía, comunión profunda con los intereses y procesos de su equipo, generando un vínculo afectivo (p. 115)

En consecuencia, el trabajo en equipo es una actividad característica de la confluencia activa y dinámica de los integrantes de un conjunto para la obtención de un objetivo o meta general para todos. No se podría hablar de trabajo en equipo propiamente - desde esta 
perspectiva - si los individuos que hacen parte del equipo llevan a cabo actividades para beneficio propio o para algunos, ya sea la mayoría o la minoría del colectivo, lo anterior está más abocado al trabajo en grupo, que necesariamente no garantiza interdependencia entre los miembros. Por lo tanto, para un trabajo en equipo deben estar incluidos todos sin excepción en pro de la finalidad; esto es, tan solo por el hecho de que una persona esté en desacuerdo $-\mathrm{y}$ que en consecuencia persiga intereses alternos al margen de los de sus compañeros - se impediría taxativamente hacer referencia a este trabajo como "labor de equipo", pues trabajar en equipo es pensar en que "me preocupo por mejorar mis conocimientos y habilidades para participar activamente en el equipo de trabajo" (Domínguez, Sierra, Sanabria, y Restrepo, 2018, p. 6). Así pues, sentirse identificado consigo mismo y con los compañeros del grupo, no solo es una actitud poco cantosa y concatenada al proceder en equipo, sino que suma y favorece a la cohesión en el proceso de las dinámicas y los intereses de cada uno.

Trabajar en equipo no es sinónimo de homogeneidad, de hecho se requiere de divergencia en cuanto a competencias de los integrantes, ya que esta interdisciplinariedad suscita discusiones, puntos de vista diferentes y múltiples soluciones a las problemáticas o inconvenientes que se presenten en el proceso para alcanzar el propósito:

Y precisamente para trabajar de forma cooperativa, es necesario desarrollar la competencia de trabajo en equipo, que existe cuando los miembros del grupo perciben que están unidos entre sí (interdependencia positiva) de forma que no pueden triunfar sin que los demás triunfen (responsabilidad individual y grupal) (Poy, Mendaña y González, 2015, p. 72)

Por otro lado, conectando el tema de la interdisciplinariedad como elemento primordial en la conformación y proceder de los equipos, se debe tener idoneidad tanto para la conformación como para la asignación de roles; un componente que se abordará a profundidad en la segunda pregunta desarrollada en este escrito. Al respecto, López, Fleta, Sardaña, Torres, y García (2017) señalan que "En este sentido, a las tradicionales fórmulas de generar equipos cuyos integrantes son seleccionados aleatoriamente o formados por el profesorado según criterios académicos, se van añadiendo otros" (p. 1269). Con base a lo señalado por los autores anteriores, la agrupación al azar delegada por quien esté a cargo es catalogada un proceder tradicional, el cual soslaya las competencias, habilidades y destrezas de cada uno de los optantes.

Q2. ¿Cómo se lleva a cabo el trabajo en equipo y qué elementos se tienen en cuenta?

Para comenzar, es pertinente mencionar que el trabajo en equipo se desarrolla luego de la correspondiente conformación de los grupos; dicho de otro modo, hasta que no se seleccionen los integrantes en relación con sus capacidades, se imposibilita cualquier proceder del colectivo. En consonancia con este requisito, se expone que la cohesión de los grupos se define generalmente por la atracción de los integrantes hacia este; es decir, la dinámica con la cual sus miembros - teniendo claro sus individualidades- demuestran 
afinidad hacia las actividades a realizar y a sus colegas (Hidayati \& Etikariena, 2018). Un recurrente problema es el tema de la vinculación de los integrantes hacia los grupos, más aún cuando la agrupación se lleva a cabo de forma aleatoria, práctica no del todo recomendada desde la concepción de trabajo en equipo, por razón de que soslaya las habilidades y destrezas de cada individuo, lo cual hace más compleja la complementación y por ende la cohesión, ya que trabajar en equipo no es sinónimo de homogeneidad, más bien de articulación sistémica entre las singularidades: "Existe una gran cantidad de estrategias que permiten a un estudiante recorrer un camino más expedito para adquirir conocimiento y estas estrategias incluyen, entre muchas otras, el trabajo en grupo" (Trejos, 2019 , p. 26). Por otro lado, luego de conformar los grupos, viene la asignación de roles y fijación de metas, que significa sentar las bases y acuerdos para la comunicación entre los integrantes de un equipo; aspecto sumamente importante, ya que regula los alcances y los medios para llevar a cabo el acto comunicativo (Were et al., 2019).

Asimismo, otro componente en la ejecución de trabajos grupales es la comunicación asertiva y la designación de un cronograma de actividades; un plan de tareas comprensivo, realista y flexible, que le permita a los miembros llevar a cabo las actividades en congruencia con el espacio y el tiempo en el que se sitúan; al respecto, García y Peláez (2017) declaran que "el trabajo en equipo como estrategia organizacional orientada a incrementar la flexibilidad en el ámbito de trabajo se ha implantado en la mayoría de las ocupaciones" ( $p$. 84). La precisión irrefutable de los procederes y los productos, al igual que la competencia feroz entre integrantes, debe ser mitigada por la armonía y las condiciones aptas para el trabajo; es decir, debe haber garantías para que los miembros del equipo puedan llevar a cabo sus tareas de forma idónea, y esto incumbe no solamente a lo que se realice de forma interna, pues los factores externos también juegan un rol significativo en el equilibrio sensible de los estados de ánimo. En lo tocante a lo anterior, se establece que las condiciones para que todo equipo pueda desempeñarse influyen de manera positiva o negativa, puesto que siempre dependerá de lo que se les provee; por lo tanto, los factores externos siempre tendrán un impacto en el proceder de los miembros de los equipos, y sus resultados reflejarán dicha influencia (Van der Hoek, Groeneveld \& Kuipers, 2016).

De este modo, entre más claridad haya sobre la integración grupal, la fijación de metas y la acción para la obtención de estas, entonces el grado de satisfacción en el proceso y en el producto serán latentes.

Q3. ¿Cuáles son los beneficios del trabajo en equipo?

Con el fin de dar respuesta a este tercer interrogante, se ha de mencionar que los aportes cantosos que el trabajo grupal puede ofrecer, se evidencian diametralmente en la medida en que su proceso sea eficiente, y dicha eficiencia se adquiere bajo una consigna innegociable en todo quehacer colectivo "la responsabilidad":

Otro valor clave implícito en todo trabajo en equipo es de 'responsabilidad': cuando falta o esta se debilita, es difícil potenciar el trabajo colaborativo y, en ocasiones, se vuelve 
imposible, pues para que sea eficaz se requiere, que todos realicen las tareas asignadas correctamente y en el tiempo establecido (Ruíz y de Rivas, 2015, p. 773)

Cuando la responsabilidad está presente, se puede decir que la confianza también, ya que la certidumbre genera estabilidad, y cada quien puede enfocarse en confianza sobre lo que le corresponde sin desconocer grosso modo el engranaje en su totalidad; la responsabilidad es una concertación meditada $a b$ initio, y un elemento connatural del trabajo en equipo.

Ahora bien, ¿cuál es el beneficio que ofrece el hecho de trabajar en equipo? En realidad son múltiples, y no es necesario meditar mucho para determinar que entre estos se encuentra la adquisición de nuevos conocimientos; resultante de todo proceso holístico e interdisciplinario. Esta adquisición no es una consecuencia estática, más bien una construcción mediante el desarrollo de competencias y habilidades a través de la labor de tareas; en palabras de Orsini, Danús y Tricio (2019), "se adquieren nuevos conocimientos, se amplían capacidades, y se valora el trabajo realizado por otros profesionales, desarrollando de esta forma habilidades propias de una disciplina como también habilidades para un efectivo trabajo en equipo" (p. 2). Recapitulando, son más los aprendizajes -no solo desde el punto de vista cognitivo- que se obtienen del trabajo en equipo en comparación a otros esquemas de trabajo, debido a que la dinámica grupal no presupone estar en contacto permanente con los miembros del equipo, más tener claridad sobre las labores a realizar y las fechas para reportar dichas labores.

Por otro lado, entre otros beneficios encontrados sobre el trabajo en equipo, se evidencia la probabilidad de argumentación, tanto de forma escrita como oral, al igual que la habilidad potencial de hablar en público y enfrentarse a una audiencia; no constituye esto un quid pro quo de independencia por interdependencia, más bien una construcción sensata que se nutre y se cataliza cada vez más por la forma en que se interactúa en los colectivos; a su vez, Herrera, Muñoz y Salazar (2017), plantean que "el trabajo en equipo de los estudiantes puede generar ciertas ventajas sobre el trabajo individual como medio parar superar algunas carencias formativas, por ejemplo, las dificultades para argumentar o para hablar en público" (p. 50). Podría incluso considerarse que esta práctica desinhibe a los integrantes, ya que el nivel de confianza incrementa por reiteración de la comunicación mediante el uso del lenguaje, con el fin de intercambiar información y construir conocimiento.

Además de la adquisición de conocimientos, el desarrollo de destrezas y habilidades, al igual que el progreso retórico en términos escritos y orales, el trabajo en equipo también ofrece ventajas desde el punto de vista psicosocial; una labor que tiene como bandera estar al tanto de los estados de ánimo de cada sujeto del colectivo. Es sabido que todas las dimensiones del ser humano están interrelacionadas; y en numerosas ocasiones, cuando hay crisis en una dimensión, este hecho atañe exponencialmente en las otras, más aun cuando el componente afectivo es al que se le hace alusión. Por tal razón, para el buen desempeño laboral y disciplinar, lo emocional debe estar estable; esto es ratificado en una investigación sobre el trabajo en equipo en profesores de primera infancia: "En los 
resultados también observamos que los profesionales que tienen menor sentimiento de equipo están más agotados emocionalmente" (Falgueras et al., 2015, p. 30). Una ventaja del trabajo en equipo es la descarga de responsabilidades, pues la obligación —que de por sí existe- no se centra en una persona; por el contrario, la dinámica del trabajo en común permite el relevo ante cualquier novedad o imprevisto, y este proceder favorece a que la cohesión entre los miembros sea más sólida en pro de la obtención de los objetivos.

Globalmente, de esta forma se da por finalizada la definición conceptual del trabajo en equipo y todo lo que conlleva, para dar paso al discernimiento temático referente al trabajo cooperativo y colaborativo.

\section{Sobre el Trabajo Cooperativo}

\section{Q4. ¿Cómo se entiende la cooperación?}

Para contextualizar, la práctica de cooperar no es algo netamente contemporáneo; si bien se ha vuelto más visible en el presente siglo, este quehacer ha estado reflejado — de forma no tecnificada - en la dinámica de grupo de múltiples disciplinas en numerables ámbitos durante décadas precedentes. Ahora bien, el aprendizaje cooperativo ha tenido una alta creciente en la pedagogía de los últimos años a nivel mundial; ha asistido en el tránsito de la educación centrada en el profesor hacia los métodos enfocados en los estudiantes; así pues, la interacción y el resultado entre pares se reivindica, gracias a la obtención de un mismo objetivo por medio del trabajo de varias personas (Yusuf, Jusoh \& Yusuf, 2019). En un acto cooperativo, sería poco probable admitir un compromiso de cero sobre cero, aunque sea solo por parte de uno de los integrantes del grupo; de hecho, la cooperación por ser de carácter grupal necesita de una alta dosis de responsabilidad, ya que las tareas pueden llevarse a cabo de forma independiente, más no de forma aislada al común o el ideal del producto. Al respecto, Estrada, Monferrer y Moliner (2016), exponen lo siguiente: "En este sentido, uno de los principales errores cometidos en iniciados en esta metodología es organizar la clase en grupos para posteriormente plantear propuestas educativas de carácter individual, esto puede ser trabajo en grupo, aunque no necesariamente cooperativo" ( $p$. 46). Aunque el trabajo cooperativo no se enfoca eminentemente en el proceso, pondera en gran proporción el desarrollo de habilidades interactivas y afectivas entre los integrantes, propiciando la ayuda mutua como algo natural en el proceso. En palabras de Slavin (2014), "El aprendizaje cooperativo hace referencia a los métodos de enseñanza en los que los estudiantes trabajan en pequeños grupos para ayudarse a aprender" (p. 785). El aprendizaje a través de la cooperación es un quehacer licencioso, el cual brinda a los miembros del colectivo una amplia gama de libertades para segmentar las tareas; y de esta forma, poder distribuir responsabilidades que engranen en el momento que dichas actividades hayan sido realizadas:

El aprendizaje cooperativo, donde los estudiantes trabajan en pequeños grupos para lograr metas compartidas, es ampliamente reconocido como una estrategia de enseñanza 
que promueve el aprendizaje y la socialización entre los estudiantes desde Educación Infantil hasta la Universidad y en las distintas materias curriculares (Gillies, 2014, p. 792)

Los integrantes que desarrollan un trabajo cooperativo no tienen la obligación de ser colectividades consumadas, las cuales operen única y exclusivamente en dependencia de sus colegas, pues - a diferencia del trabajo colaborativo- el producto es dirigido por el docente, instructor, profesor, o persona encargada de la conformación de los grupos y la asignación de los roles. Esto ayuda a que la experiencia esté mediada constantemente por esta persona, la cual debe procurar que se desarrolle un aprendizaje entre los sujetos del grupo. Sobre este aspecto, Palomino (2018) refiere que "para ello, se plantea una experiencia de aprendizaje cooperativo, entendida ésta como metodología básica de enseñanza y aprendizaje a través de la realización de trabajos grupales entre el alumnado" (p. 833).

Por otro lado, se hace preciso discernir —más no desde el deseo extremo por diferenciar taxativamente entre un concepto y otro- lo que normalmente se conoce como aprendizaje cooperativo en vez de colaborativo. El trabajo cooperativo es de connotación grupal, mas su énfasis no está en el desarrollo de las tareas de forma holística; es decir, el individuo no necesita estar al tanto de todo lo que concierne al producto final. Este debe preocuparse más por el cómo se gestan las relaciones comunicativas y afectivas entre miembros; y consecuentemente, poseer un alto nivel de responsabilidad para responder por el desarrollo de la tarea que le fue encomendada realizar, la cual será concatenada a las otras al final del proceso:

En primer lugar, se hace necesario diferenciar los términos cooperar y colaborar, ya que habitualmente ambas palabras se emplean como sinónimas cuando en realidad no significan lo mismo. Cooperar implica una serie de valores relacionados con el desarrollo personal del alumnado que no contempla la colaboración (Lata y Castro, 2016, p. 1093)

En el aprendizaje cooperativo, no se requieren condiciones de tiempo y forma para que un integrante del equipo esté en propiedad de llevar a cabo la actividad de otro, más bien existe el compromiso de que esa persona que no pudo realizar la tarea que le fue asignada, busque los medios para responder en gran medida por este deber. Este proceso debe ser gestionado por ese sujeto y sus compañeros no son responsables por su producto. Asimismo, aunque la responsabilidad sea un elemento individual en la cooperación, se reivindica la interacción del colectivo; esta habilidad hace que los problemas se solventen con soluciones propuestas por los miembros. No obstante, la solución la debe ejecutar aquella persona que se encuentra en el problema, aunque con ayuda de sus compañeros:

En ocasiones suele utilizarse indistintamente aprendizaje colaborativo y cooperativo, si bien se hace preciso matizar que, aunque se muestren semejantes en varios aspectos, en el aprendizaje cooperativo no importa sólo el logro del resultado final, sino la propia interacción entre los miembros del grupo, siendo igualmente relevantes para el aprendizaje, el proceso y el resultado (Pérez, Sierra y Quijano, 2018, p. 12) 
Como se mencionó anteriormente, el "análisis" prematuro de las concepciones entre cooperar y colaborar, trae a colación el rol de la persona encargada de conformar los grupos de trabajo; pues en la cooperación, el docente, profesor, instructor o encargado, es el eje central durante todo el proceso, tanto desde su concepción, su desarrollo, como en la concreción de las tareas y obtención de objetivos. Las directrices establecidas ofrecen mayor control por parte del encargado y, en este sentido, este tiene la posibilidad de observar el desempeño que cada quien está teniendo durante el progreso de las labores:

Una de ellas la encontramos en el deslinde preciso del trabajo cooperativo y el colaborativo; así, mientras el primero supone una dirección más estricta y formal por parte del profesor, el colaborativo permite mayor grado de autonomía del alumno. Sin embargo, las ventajas del aprendizaje cooperativo justifican su aplicación en esta experiencia, por cuanto el control de las actividades de los estudiantes es un objetivo que consideramos conveniente. (Cebrián, Moreno y Rodríguez, 2014, p. 71)

De esta forma, se concluye el segmento que define a la cooperación, y la distancia, a su vez, un poco de la connotación colaborativa a la que en numerosas oportunidades ha sido sometida, ya sea por la volatilidad lexical o por el desconocimiento inherente de su desarrollo.

Q5. ¿Cuáles son los elementos que permiten llevar a cabo un aprendizaje cooperativo?

Entre los componentes sustanciales para que el trabajo cooperativo sea puesto en escena, se encuentra la implementación de una serie de directrices para la "armonía" en los procesos. Estas instrucciones son dadas por la persona encargada de la conformación de los grupos, y están ligadas al análisis a posteriori de las dinámicas entre los sujetos potenciales a ser agrupados. En este sentido, en todo trabajo cooperativo debe haber parámetros preestablecidos que obedezcan a las intencionalidades didácticas, pues no puede haber cooperación en los miembros de un equipo sin una previa reflexión de quien lo conforma sobre el acto educativo (Sardi et al., 2018).

En lo tocante a la conformación de equipos de trabajo, se puede decir que es un componente que tanto en la modalidad cooperativa como colaborativa se debe compartir, pues aunque estas dos presentan matices diferenciales, también comparten aspectos connaturales del aprendizaje en colectivos. Por otro lado $-\mathrm{y}$ siguiendo el principio anteriormente mencionado - en el aprendizaje cooperativo se deja de lado inclusive una posibilidad semi-involuntaria del proceder en los sujetos, puesto que -entre muchas otras labores - "el docente" se hace cargo de la toma de decisiones, aspecto que lo pone como responsable y garante de los procederes y los resultados. Esto conlleva a entender que: "aprender a aprender cooperativamente requiere varios cambios tanto en los profesores como en los alumnos: en su percepción del aprendizaje, en sus actitudes hacia la enseñanza y el aprendizaje, y en sus comportamientos sociales y cognitivos en el aula" (Sharan, 2014, p. 802). 
Cuando el encargado de la organización grupal ya ha analizado a todos los individuos para agruparlos, el paso a seguir es la visualización e instalación de las metas a alcanzar; esto es otro aspecto que también se comparte entre las connotaciones cooperativas y colaborativas. A su vez, Serrano \& Pons (2014), manifiestan lo siguiente, "El objetivo principal de esta revisión es la defensa del aprendizaje cooperativo como una estrategia altamente efectiva para el logro de las metas generales del aprendizaje" (p. 781). El tema de la fijación de objetivos, no es una función intrínsecamente de mentes prodigiosas, más bien diligentes; y es aquí donde nuevamente el docente hace su aparición, ya que -si bien es el encargado de controlar todo el quehacer en los miembros del grupo- es igualmente responsable de efectuar cambios durante la ejecución de las actividades; espacios para incluir futuros logros emergentes para obtener de forma idónea el producto final:

Los miembros del equipo han de establecer objetivos de manera periódica, que aseguren que están funcionando bien como equipo, a la vez que han de identificar cambios que les permitan funcionar del modo más efectivo en el futuro, referentes a planificación de tareas, gestión del tiempo, etc. (Hurtado \& Lara, 2015, p. 139)

Entre otros componentes sustanciales para el trabajo cooperativo se encuentra la interacción, expresión recurrente entre las dinámicas de grupo, más empresa eminentemente compleja al momento de poner en manifiesto. Se expone este tema, por razón de que siempre habrá momentos de turbulencia durante el trabajo, en los cuales muchas veces los integrantes de los equipos carecen de competencias emocionales para limar asperezas; otro punto a favor para el docente, quien en la modalidad de trabajo cooperativo está a cargo de intervenir en situaciones de desconcierto, ya sea desde lo temático, lo metodológico o afectivo. Sobre la necesidad de interactuar durante los grupos de trabajo de corte cooperativo, Bellmunt, Torres, Vallet y Bellmunt (2016) afirman que "los 2 elementos clave de esta teoría son el aprendizaje activo y la interacción con compañeros" (p. 18). En este orden de ideas, todo indisciplinado, todo agresivo, todo socarrón, entre otros; deberá auto-regularse durante la labor grupal; de lo contrario, el docente intervendría para garantizar la armonía en pro de las generalidades. Esto es uno de los numerosos aspectos que conlleva trabajar bajo la modalidad cooperativa; quehacer que requiere cambio de paradigma; verbigracia: "como la resistencia a trabajar de manera cooperativa, la falta de cohesión y entendimiento entre los componentes del equipo y la desconfianza ante la implementación de una evaluación poco conocida" (Martín y Cid, 2018, p. 291).

Sobre la tan mencionada interacción, se hace imposible soslayar el medio virtual. Hoy por hoy, en gran medida la comunicación se desarrolla a través de múltiples aparatos electrónicos, y dicha manera ha alterado - ya sea para bien o para mal- las formas convencionales en las que el ser humano intercambiaba ideas. Así pues, en una investigación sobre aprendizaje cooperativo y redes sociales, Castaño, Maíz y Gara (2014), declaran que "a lo largo del curso y en el desarrollo de las e-actividades propuestas, se insistió en la utilización de las redes sociales para conseguir que los estudiantes cooperaran entre ellos y también con los profesores del curso" (p. 127). 
Para finalizar con este apartado, la interacción de igual forma -además de todo lo comentado anteriormente- es más eficaz durante un trabajo en equipo que se nutra de múltiples vertientes; imposición de manos colectiva -en términos metafóricos- que garantizaría tanto la divergencia como la convergencia de opiniones y competencias, en pro de alcanzar el tan anhelado objetivo común: "En un mundo cada vez más interdependiente, cobran especial importancia aquellas competencias relacionadas con el trabajo en equipo que permitan trabajar cooperativamente con profesionales procedentes de distintas disciplinas" (Soria, Gómez, Monsalve y Pérez, 2015, p. 99).

Q6. ¿Qué favorece el hecho de trabajar cooperativamente?

Entre las numerosas ventajas de trabajar de forma cooperativa, se encuentra el aumento en los niveles académicos por parte de los estudiantes, al igual que la implementación de nuevas estrategias de aprendizaje. Los estudiantes pasan de ser pasivos a proactivos de forma inherente a la dinámica de trabajo; y de igual forma, extrapolan dichas cualidades a otras labores académicas:

Algunas de las conclusiones fueron las siguientes: se asume que el aprendizaje cooperativo tiene incidencia en tres niveles: académico, social y personal; se encontró que en el grupo experimental, los estudiantes tuvieron una mejora en su desempeño académico en lo referente al empleo de estrategias de aprendizaje; en el trabajo cooperativo los estudiantes tienen actitudes proactivas hacia las tareas y en justificar sus razonamientos ante sus compañeros, al tiempo que escuchan otros razonamientos (Morales, García, Torres \& Lebrija, 2018, p. 53)

En este sentido, la proactividad es uno de los tantos resultantes del trabajo cooperativo, en el cual los integrantes del equipo -a pesar del control por parte del docente- actúan con desenvoltura, y dicho comportamiento es latente en los procederes activos. Lo conocido como aprendizaje activo se replica, de igual forma, en contextos al margen de las tareas cooperativas; desarrollando en los miembros del colectivo, iniciativas hacia la contribución y colaboración hacia otros. Del mismo modo, en un estudio sobre la integración entre dinámicas de aprendizaje individual y cooperativo, se encontró que:

En general, la incorporación de diferentes técnicas de aprendizaje cooperativo y de una práctica competitiva a una materia de química de los materiales ha demostrado ser una herramienta muy útil para fomentar un aprendizaje activo sin perder de vista las ventajas de una enseñanza llevada a cabo con metodología tradicional (Lazzari, 2014, p. 45)

Aparte del aprendizaje activo y el incremento en el desempeño académico, el aprendizaje cooperativo proporciona solidificación afectiva entre pares, pues aunque cada quien se debe encargar de tareas específicas - fusionables al final del proceso- el contacto y comunicación de forma o no temporal y espacial, permite que los sujetos compartan asuntos, los cuales no necesariamente deben ser de carácter académico. Sobre esta cualidad, del Río, Lázaro, Bullón y del Barco (2017), manifiestan que "el aprendizaje cooperativo puede ser una solución que posibilite la creación de relaciones de alta calidad entre iguales y proporcione a los alumnos esas estrategias básicas necesarias, para desarrollar unas adecuadas interacciones interpersonales" (p. 4). 
Finalmente, las dúctiles posturas de comportamiento son un elemento anexo, el cual se tiende a desvanecer gracias a la dinámica cooperativa; otro gran aporte en este tipo de modalidad, puesto que el acoso escolar - realidad pura y dura en el día a día de la comunidad educativa - se manifiesta en múltiples ambientes, sin importar muchas veces la presencia o no de una figura que represente la autoridad. En una investigación sobre la dinámica bullying y el aprendizaje cooperativo, se encontró lo siguiente: "En primer lugar, nuestros resultados indican que se ha producido una reducción significativa del acoso escolar (agresiones de exclusión social y agresiones verbales y físicas directas) como consecuencia de la intervención en aprendizaje cooperativo" (León, Polo, Gozalo \& Mendo, 2016, p. 85). El aprendizaje cooperativo no es considerado una modalidad rutilante en lo concerniente al trabajo en equipos; sin embargo, sus aportes demuestran ser altamente funcionales para obtener resultados tanto de corte cognitivo, comportamental y afectivo.

Q7. ¿Qué es lo que se conoce por aprendizaje colaborativo?

Para abordar conceptualmente lo referente al trabajo colaborativo, se debe dejar claro que es otra modalidad de trabajo grupal; forma que comparte matices con la dinámica cooperativa, pero que se distancia de esta sustancialmente en su proceder. Entre las características más marcadas se encuentran las que exponen López y Molina (2018), quienes afirman que "este tipo de estrategia se enmarca en procesos de interformación, en los que los miembros aprenden mutuamente y reconfiguran el objeto de estudio a partir del diálogo, la participación y la co-construcción del conocimiento" (p. 2); a lo que Antonio et al. (2017) agregan: "puede decirse por lo anterior que el trabajo colaborativo consiste en trabajar con otra u otras personas para alcanzar una meta" (p. 338).

A diferencia del trabajo cooperativo, en el aprendizaje colaborativo no se percibe el estatismo durante los momentos de toma de decisiones, esto a razón de que los estudiantes son autónomos para delegar roles dentro de sus respectivos equipos, y en esto el docente estaría al margen, ya que la comunicación asertiva entre individuos facilitaría la dinámica y la democracia dentro del colectivo. En las dinámicas colaborativas, cada estudiante se expresa con libertad en aras a la toma de decisiones procedimentales, las cuales marcan el rumbo durante el desarrollo de las actividades. Sobre esto, De Castro y Portolés (2017) establecen que "para que esta horizontalidad sea efectiva, la colaboración es esencial y cada uno de los miembros realiza sus aportaciones desde su experiencia, trayectoria y disponibilidad" (p. 25). Por consiguiente, el proceso participativo puede -en algunas ocasiones - llegar a ser increíblemente agitado, visto que la figura representativa de la autoridad (el docente) es ausente durante el proceso de aprendizaje colaborativo; por lo tanto, la madurez para encontrar las rutas por las cuales transitar, depende única y exclusivamente de cada integrante del equipo. Obviamente, siempre aparecerán figuras que intrínsecamente se potencian como "líderes"; no obstante, deben emerger de forma natural, sin intervención o asignación de la persona a cargo de la conformación de los grupos; aspecto preponderante que se discutirá más adelante.

Durante los procederes colaborativos, existe intercambio de opiniones en los cuales el docente no interviene durante el proceso, a no ser que taxativamente se requiera su presencia. Asimismo, no es usual que en esta modalidad el docente se inmiscuya durante el trabajo autónomo de los estudiantes en los equipos de trabajo: 
La formación entre compañeros de trabajo lleva al aprendizaje colaborativo entre profesionales y se entiende como un proceso de aprendizaje en "feedback", ya que cada participante aporta conocimiento al grupo y a la red de la que forma parte, se forma en el grupo y vuelve de nuevo al grupo de trabajo para su puesta en común a través de prácticas consensuadas (Montaño, Martínez y Torre, 2017, p. 653).

Una de las grandes diferencias entre el trabajo cooperativo y colaborativo es la asignación de tareas y su respectiva resolución, ya que en el primero se dividen para ser yuxtapuestas al final y así presentar la suma de singularidades, mientras que en el segundo cada individuo que hace parte de la colectividad debe estar al tanto de su trabajo y del de sus compañeros; flexibilidad y pertinencia que pueden ser útiles en diferentes estancias del trabajo mancomunado:

El valor de la metodología basada en el aprendizaje colaborativo reside en que se produce una unión e intercambio de esfuerzos entre los integrantes que conforman el grupo, de tal manera que el objetivo común y grupal que se persigue origine, al final del proceso, un beneficio individual en todos y cada uno de los participantes (Muñoz y Tejedor, 2018, p. 156).

Por tal razón, el proceso de aprendizaje radica en los estudiantes; situación edulcorada que impide un proceso reglado, y más bien constituye un alto grado de cohesión desde las habilidades inter e intrapersonales que se pueden desarrollar durante el contacto - ya sea presencial o virtual- entre miembros del equipo. Así pues, todos deben estar al tanto de la labor que está llevando a cabo el compañero; esto permite que puedan intercambiar o relevar labores, en caso tal de que uno de los integrantes demuestre dificultad o imposibilidad de desarrollar un determinado quehacer. Dicho de otra manera, Fombona, Iglesias y Lozano (2016) exponen que "en suma, se puede afirmar que el alumnado considera que el trabajo colaborativo se basa en llevar a cabo un proyecto común, en el que todos los participantes colaboren de manera activa aportando ideas mediante una buena interacción social" (p. 529). Dándole continuidad a la autonomía que deben tener los estudiantes en cuanto a la toma de decisiones, es imperativo mencionar que los miembros del equipo deben ser muy responsables con el proceso educativo en general, ya que trabajar colaborativamente es comprender cada uno de los aspectos. En este sentido, una y varias tareas son realizadas por todos sin excepción, cada miembro debe aportar en el desarrollo de cada actividad; por lo cual, el trabajo individual para ser cohesionado al final del proceso no tiene lugar en esta modalidad. En un estudio sobre trabajo colaborativo comunitario entre mujeres, Koh y Castillo (2014), encontraron que:

A partir de lo mencionado, en conjunto, se estableció que el objetivo general fuera desarrollar un trabajo colaborativo que estuviera orientado a favorecer el desarrollo de estrategias que fomentaran el apoyo social entre este grupo de mujeres y las personas a su alrededor (p. 125)

Finalmente, se puede referir que el trabajo colaborativo representa poca intervención del docente, en cuanto al desarrollo de actividades por parte de los estudiantes durante el proceso. Asimismo, los roles son definidos por estos y son del mismo modo libres de 
establecer reglas internas bajo un presupuesto con cariz democrático. Las tareas no se dividen, estas deben ser realizadas por todos, manejando las realidades del espacio-tiempo, razón por la cual el proceso se valora mucho más que el producto, sin dejar de lado que el segundo es una consecuencia lógica del primero. Dicho lo anterior, no todas las alternativas y variables en la ejecución del aprendizaje colaborativo son impensables, pues si el docente analiza y cree que debe intervenir a causa del mal funcionamiento de uno o más grupos en particular —durante el desarrollo de las tareas—, entonces puede hacerlo para restablecer el curso hacia la obtención del objetivo principal. Consecuentemente, Järvelä (2015) manifiesta que "en definitiva, investigaciones previas han demostrado la necesidad de facilitar apoyo en las dificultades de la colaboración, en relación con las metas cognitivas, motivacionales y emocionales de los procesos de grupo" (p. 289). Para concluir, el trabajo en equipo bajo la modalidad colaborativa da muestras de flexibilidad y su naturaleza lo encauza en poblaciones con destrezas y habilidades específicas.

Q8. ¿Cómo se desarrollan las dinámicas colaborativas?

El primer paso para desarrollar un aprendizaje colaborativo -como cualquier otra dinámica de trabajo grupal- es la selección de las personas con las cuales se pretende trabajar. Esta selección puede ejecutarse de varias maneras: el docente o persona a cargo expone un número-requisito que describe la cantidad máxima y/o mínima de los integrantes en las colectividades. En segundo lugar, existen dos alternativas: el docente concede libertad a los sujetos para que se agrupen de acuerdo a sus respectivas complacencias, o estos pueden ser agrupados con base a las percepciones e intenciones del docente. Analizar las particularidades de los estudiantes para la conformación de equipos, puede ser un aspecto compartido visible también en la modalidad cooperativa: "los procesos de trabajo colaborativo están influenciados por el estilo personal y el comportamiento individual de cada uno de los miembros del grupo" (Jaime \& Lizcano, 2015, p. 61). Asimismo, se declara que, en la escuela, se recomienda que los grupos sean conformados por el docente, quien conoce las singularidades, habilidades y competencias de sus estudiantes. Esto beneficia al trabajo colaborativo, pues el hecho de tener comprensión sobre las habilidades de los aprendices, permite la designación de roles a desempeñar con mayor certeza; para que todos trabajen hacia un mismo objetivo desde la singularidad, en vez de unir fragmentaciones para generar un producto (Corredor \& Pinzón, 2018).

En tercer lugar, luego de contar con las personas a trabajar, se tiene la asignación de roles dentro del equipo de trabajo. En la modalidad colaborativa, el docente debe estar al margen de esta empresa, ya que depende inexorablemente de la autonomía de los miembros; a su vez, el diálogo y la comprensión deben estar presentes en todo momento, pues como se menciona, la trasparencia en todo trabajo colaborativo hace parte de la ética que se requiere, por lo que se debe tener cuidado con las nuevas formas de interacción que se viven en la contemporaneidad, las cuales propenden a que las personas de los grupos ya sean grandes o pequeños- comuniquen información muchas veces producto de los 
impulsos, más no dé la razón (Robbins \& Giaccardi, 2019). Aquí ya se adentra un poco a la dinámica interactiva de los individuos -que luego de conocer el papel que van a desempeñar en el equipo- deben desarrollar las tareas que ayudarán alcanzar el objetivo principal. En este sentido, las TIC cobran fuerza hoy por hoy, puesto que los recursos disponibles para la comunicación y la realización de actividades brindan a los integrantes del grupo ventajas que décadas atrás no se tenían:

En el pasar de los años no se puede decir que el aprendizaje colaborativo se ha redefinido, más bien se ha adaptado a las nuevas herramientas TIC que han surgido, como son la mensajería instantánea, los foros, las wikis, los blogs, los microblogs, las redes sociales, la marcación social, etc. (Avello \& Duart, 2016, p. 273)

A decir verdad, a pesar de que en el pasado no se contaba con los recursos tecnológicos de esta era, las personas podían llevar a cabo prácticas colaborativas eficientes de igual manera. Algunos jóvenes de hoy día, perciben que antes de la aparición de las computadoras, el ser humano podría estar viviendo en un bucle espacio-temporal, en el cual la falta de contacto permanente - por efectos de largas distancias - impedía la agilidad de los procesos. No obstante -aunque la distancia era un factor determinante en los trabajos grupales - la memoria se ponderaba y se valoraba aún más la palabra. Dándole continuidad a las dinámicas contemporáneas, aparecen los recursos TIC como dinamizadores durante el trabajo colaborativo, aspecto que Soto (2011) reitera en cuanto menciona que "esta nueva manera de interactuar en Internet favorece el trabajo colaborativo y el autoaprendizaje mediante la combinación de una serie de herramientas" (p. 72). A su vez, Ruiz (2014) agrega que:

En general, en el contexto universitario hoy en día, el docente-mediador debe ser consciente de que estas herramientas encaminadas al aprendizaje colaborativo resultan sumamente apropiadas tanto para el desarrollo de competencias profesionales como para reforzar la adquisición de competencias transversales (p. 225)

Si bien la tecnología ha propiciado nuevas formas de interacción, no se le puede culpar a los aparatos lógicos, físicos e inertes, por el mal uso que el ser humano de estos hace. Llega a ser común escuchar personas de otras generaciones, reprochar acerca del caos en el que vivimos, superponiendo a la tecnología como máquinas y dispositivos que corrompen a la humanidad. Por más importantes que sean estos aparatos, siempre serán reemplazados; nuevos artilugios aparecerán y lo que es novedoso hoy mañana no lo será. En la memoria siempre estarán aquellas personas que dejaron huella en este mundo, más no los instrumentos o mecanismos que estas utilizaban. Por lo cual, y para dar término a este componente, el trabajo colaborativo será necesario en el futuro, así como lo es hoy y como lo fue en el pasado:

Si se analiza a profundidad, la forma en la que se trabaja dentro de ambientes colaborativos no ha cambiado significativamente a través de los años, más aún, la tecnología no ha logrado desplazar el uso de herramientas tradicionales de trabajo colaborativo (Quiñonez, Luzardo y Granda, 2016, p. 67) 
Q9. ¿Cuáles son los elementos que reivindica el hecho de trabajar colaborativamente?

Al igual que las prácticas cooperativas, la colaboración trae consigo una serie de desarrollos procedimentales por parte de los integrantes que trabajan bajo esta modalidad; entre estos se encuentra el aprendizaje interdependiente, que no es asunto baladí de trabajar al lado de alguien, mas es la capacidad de confiar en el trabajo del compañero, partiendo de la conciencia sobre sus capacidades:

A partir de la apropiación de las características de interdependencia positiva. Todo ello permite alcanzar más fácilmente los objetivos de aprendizaje cuando son parte de un equipo colaborativo, por lo tanto, resulta un mecanismo efectivo para maximizar su propio aprendizaje y el de los demás individuos (Almanza, Monobe y Barceló, 2018, p. 3)

Desarrollar la sensibilidad de trabajar entre pares no es algo sencillo, ipor muy fácil que parezca!, pues es común que profesionales y académicos consumados prefieran la construcción del conocimiento de forma individual, mirando de soslayo al otro para evitar obstáculos en la obtención de objetivos, esto se debe a que no tuvieron la oportunidad de desarrollar esta destreza en procesos grupales precedentes, lo que les complica llegar a acuerdo con sus compañeros de trabajo y ceder - aunque sea un poco- en las ideas que el otro proponen en el día a día laboral. Por lo tanto, el aprendizaje colaborativo ayudaría a movilizar estructuras aparentemente inamovibles entre los sujetos de una colectividad:

El trabajo colaborativo en red entre profesionales ha demostrado en este estudio que genera conocimientos compartidos, promueve la adquisición de experiencias y apoya el desarrollo profesional del profesorado más allá del aula, es un aprendizaje intencional como proceso de intercambio de conocimientos y creación de los mismos (de la Torre y Montaño, 2018, p. 35).

Desde luego, el trabajo colaborativo no es el elixir ante la desolación y tristeza, porque el fin de esta modalidad grupal rara vez se enfoca en aspectos afectivos, más bien académicos y laborales. No obstante, el hecho de poner la atención en el proceso del compañero, y no centrarse intransigentemente en una tarea personal, permite conocer otros aspectos de la vida de ese sujeto que trabaja al lado, de esa persona que aparte de sus deberes en su ocupación, también posee una vida de anhelos, dudas, disgustos, problemas, entre otros; algo que se conoce a través del contacto horizontal entre miembros. Al respecto, Briede, Leal, Mora y Pleguezuelos (2015), declaran que "el proceso de enseñanza/aprendizaje colaborativo de la observación permite un conocimiento que parte de la experiencia y que a través del diálogo, el consenso y la reflexión conjunta, reconstruye saberes en una interacción comunicativa de carácter horizontal" (p. 25). La participación efectiva promueve el aprendizaje y la resolución de problemas.

Otro beneficio que trae consigo el hecho de trabajar colaborativamente es el incentivo extrapolable del uso de recursos tecnológicos, pues recientemente se ha apreciado que cuando las personas utilizan las TIC para trabajar de forma colaborativa, replican dichas competencias en otros quehaceres que necesariamente no se llevan a cabo de forma grupal. Por tal razón, este tipo de ayudas son usadas en diversos contextos cada vez más: 
En los últimos años el aprendizaje colaborativo apoyado por computador o CSCL (por sus siglas en inglés para Computer Supported Collaborative Learning) ha sido impulsado por los profesores al interior de las aulas de clase con el objetivo de ampliar y diversificar los procesos de adquisición y generación de nuevos conocimientos, aprovechando así las ventajas brindadas por los entornos de aprendizaje colaborativo (Álvarez, Salazar y Ovalle, 2018, p. 290)

Apoyando esta sentencia - aunque suene cansino para algunos- las redes sociales también han sido de gran apoyo en el desarrollo de destrezas tecnológicas que suelen ser utilizadas para momentos de ocio u otras actividades análogas, debido a que luego de ser empleadas colaborativamente con fines académicos y/o laborales, su utilidad perdura para nuevas formas de trabajo al cabo de las prácticas colectivas. En una investigación sobre el uso de la red social Facebook en prácticas colaborativas, se encontró lo siguiente:

Se concluye que fue posible personalizar el aprendizaje colaborativo en Facebook con la construcción de la aplicación Sigma. Sin embargo, contrario a lo esperado, el uso de un grupo Facebook fue aceptado por los estudiantes que participaron en el experimento como la mejor alternativa para el uso de esta plataforma en el aprendizaje colaborativo (Reyes, Fernández, Pérez y Urrutia, 2018, p. 65)

Posiblemente, a través del trabajo colaborativo muchas más habilidades puedan ser desarrolladas; a su vez, esta revisión literaria nos muestra las más marcadas en la contemporaneidad.

\section{Conclusiones}

Inicialmente, el hecho de expresar que una modalidad de trabajo grupal es mejor o peor que otra sería pronunciarse a priori sobre lo que sus dinámicas implican, ya que la elección debe depender de las necesidades tanto del contexto como de la población, "utilizando como estrategia diálogos reflexivos para evaluar en conjunto la pertinencia de las actividades de aprendizaje según las características y necesidades del cuerpo estudiantil" (Mellado, Chaucono, Hueche y Aravena, 2017, p. 122). Así pues, las singularidades de los estudiantes deben ser tenidas en cuenta, si lo que se pretende es asignar grupalmente de acuerdo a fortalezas y debilidades de los potenciales miembros.

En lo tocante a las edades cronológicas, se percibe que el trabajo cooperativo es más latente en ejercicios grupales con poblaciones de menores edades, pues las cualidades para el trabajo colaborativo requieren más madurez y control por parte de sus integrantes, ya que su carácter flexible y emancipatorio en el aprendizaje, depende de cuán capaces de timonear los procesos sean los miembros de la colectividad. En consonancia, Carrasco, Alarcón y Trianes (2018) apuntan:

Al comenzar el recorrido del trabajo defendíamos el aprendizaje cooperativo, posiblemente sin argumentos, como una herramienta promotora de la interacción entre los niños/as frente a el individualismo, sin embargo, teníamos dudas sobre si funcionaría 
en Educación Infantil. Ahora, al acabar este trabajo, podemos afirmar que, este tipo de proceso enseñanza-aprendizaje es una de las soluciones a la estructura y los valores de la sociedad en la que vivimos (p. 103).

En todo trabajo en equipo debe estar presente tanto la comunicación como la responsabilidad, pues aunque la dinámica varíe de acuerdo a su naturaleza (cooperativa o colaborativa), el trabajo en equipo sería nulo sin ninguna de estas dos. Por lo tanto, el esfuerzo con avidez es parte fundamental en la construcción de conocimiento entre pares a través del diálogo asertivo: "La comunicación es la capacidad que tiene todo ser de relacionarse con el entorno. Es el intercambio de opiniones en busca de relacionarse con dos o más personas" (Villamil, 2017, p. 10).

La persona encargada de establecer los objetivos principales a alcanzar en el trabajo grupal, es una figura representativa y facultativa que siempre debe estar presenta, ya sea de forma permanente o intermitente de acuerdo al tipo de modalidad grupal. Declarar a corazón abierto que no es necesaria su presencia, es comenzar a desconocer que existen reglas en toda dinámica académica y laboral; por lo cual, una figura que dirija el norte de todo trabajo en equipo o en grupo será siempre necesaria en los procederes tanto cooperativos como colaborativos (Gasca et al., 2015).

El aprendizaje en equipo reivindica con creces las formas contemporáneas del aprendizaje, puesto que reúne múltiples enfoques pedagógicos, provenientes de corrientes representativas del constructivismo y del movimiento crítico-social. Ambas consignan en sus representantes, la visión de que se aprende cuando se está en contacto con el ambiente, con el otro y consigo mismo; Benmelej, Iugman, Aró y Villafañe (2016) determinan que "este concepto explica la importancia de los pares en el proceso de aprendizaje y tiene una relación directa con el aprendizaje colaborativo. Su visión aporta a la teoría constructivista la importancia del aprendizaje grupal" (p. 3).

\section{Referencias}

Álvarez, S., Salazar, O. M., y Ovalle, D. A. (2018). Modelo basado en Agentes para la Detección de Fallas Cognitivas en Entornos de Aprendizaje Colaborativo. Información tecnológica, 29(5), 289-298. https://doi.org/10.4067/S0718-07642018000500289

Almanza, J. L., Monobe, A., y Barceló, V. (2018). Aprendizaje activo para el desarrollo de la psicomotricidad y el trabajo en equipo. Revista Electrónica Educare, 22(1), 319-344. https://doi.org/10.15359/ree.22-1.16

Antonio, J. M. V., Mosqueda, J. S. H., Vázquez, A. J., Hernández, L. G. J., y Calderón, C. E. G. (2017). El trabajo colaborativo y la socioformación: un camino hacia el 
conocimiento complejo. Educación y Humanismo, 19(33), 334-356. https://doi.org/10.17081/eduhum.19.33.2648

Avello M. R., y Duart, J. M. (2016). Nuevas tendencias de aprendizaje colaborativo en elearning: Claves para su implementación efectiva. Estudios pedagógicos (Valdivia), 42(1), 271-282. https://doi.org/10.4067/S0718-07052016000100017

Bellmunt, T., Torres, P., Vallet, B., y Bellmunt, A. (2016). Eficiencia del plan de marketing como técnica de aprendizaje cooperativo. European Research on Management and Business Economics, 22(1), 17-24. https://doi.org/10.1016/j.iedee.2015.09.001

Benmelej, L. B., Iugman, J., Aró, C., y Villafañe, N. (2016). Modelo de aprendizaje activo para el estudio de las ciencias morfológicas. Morfovirtual, (1), 1-6. http://www. morfovirtual2016.sld.cu/index.php/Morfovirtual/2016/paper/download/ $232 / 81$

Briede, J. C., Leal, I. M., Mora, M. L., y Pleguezuelos, C. S. (2015). Propuesta de modelo para el proceso de enseñanza-aprendizaje colaborativo de la observación en diseño, utilizando la pizarra digital interactiva (PDI). Formación universitaria, 8(3), 15-26. https://doi.org/10.4067/S0718-50062015000300003

Carrasco, C., Alarcón, R., y Trianes, M. V. (2018). Adaptación y trabajo cooperativo en el alumnado de educación primaria desde la percepción del profesorado y la familia. Revista de Psicodidáctica, 23(1), 56-62. http://dx.doi.org/10.7203/CREATIVITY.1.12064

Castaño, G., Maiz, O., y Gara, R. (2014). Redes sociales y aprendizaje cooperativo en un MOOC. Revista Complutense de Educación, (26), 119-139. https://doi.org/10.5209/rev_RCED.2015.v26.46328

Cebrián, F., Moreno, J., y Rodríguez, M. (2014). Aprendizaje cooperativo en educación superior: diferencias en la percepción de la contribución al grupo. Universities and Knowledge Society Journal, 11(2), 70-84. http://dx.doi.org/10.7238/rusc.v11i2.1936

Collazos, C. A., \& Mendoza, J. (2006). Cómo aprovechar el "aprendizaje colaborativo" en el aula. Educación y educadores, 9(2), 61-76.

Corredor, J., \& Pinzón, B. (2018). Advanced learning methodology, based on action research and collaborative work for the teaching of high performance computing. Journal of Physics: Conference Series, 1126(1), 1-7. https://doi.org/10.1088/1742$6596 / 1126 / 1 / 012044$ 
Daza, W. G. I. (2018). Investigación educativa desde un enfoque cualitativo: la historia oral como método. Voces de la educación, 3(6), 93-110. https://dialnet.unirioja.es/servlet/articulo?codigo $=6521971$

De Castro, P., y Portolés, A. (2017). Movimiento pendular: proyectos de educación patrimonial entre la esfera formal y la informal. El Programa Pintia de Innovación Educativa y la Fiesta del Vino de Viver. Estudios pedagógicos (Valdivia), 43(4), 7-28. https://doi.org/10.4067/S0718-07052017000400001

De la Torre, E., y Montaño, M. (2018). Redes educativas locales para la mejora escolar. REDIE: Revista Electrónica de Investigación Educativa, 20(3), 29-42. https://doi.org/10.24320/redie.2018.20.3.1669

Delgado, A. L. M., y Herreño, V. M. B. (2018). Revisión Documental: El estado actual de las investigaciones desarrolladas sobre discriminación hacia personas con discapacidad auditiva en países Latinoamericanos de habla hispana entre los años 2009 al primer trimestre de 2018 [Tesis de Maestría, Corporación Universitaria Minuto de Dios]. https://repository.uniminuto.edu/handle/10656/6807

Del Río, M. I. P., Lázaro, S. M., Bullón, F. F., y del Barco, B. L. (2017). Una intervención en aprendizaje cooperativo sobre el perfil del observador en la dinámica bullying. Universitas Psychologica, 16(1), 1-13. https://doi.org/10.11144/Javeriana.upsy161.iacp

Domínguez, L. C., Sierra, D., Sanabria, Á., y Restrepo, J. (2018). ¿Soy parte del equipo?: transformando las percepciones estudiantiles en un instrumento para evaluar el trabajo en equipo en cirugía. Educación Médica, 1-8. https://doi.org/10.1016/j.edumed.2018.11.005

Estrada, M., Monferrer, D., y Moliner, M. A. (2016). El Aprendizaje Cooperativo y las Habilidades Socio-Emocionales: Una Experiencia Docente en la Asignatura Técnicas de Ventas. Formación universitaria, 9(6), 43-62. https://doi.org/10.4067/S071850062016000600005

Falgueras, M. V., Munoz, C. C., Pernas, F. O., Sureda, J. C., López, M. P. G., y Miralles, J. D. (2015). Burnout y trabajo en equipo en los profesionales de Atención Primaria. Atención Primaria, 47(1), 25-31. https://doi.org/10.1016/j.aprim.2014.01.008

Fombona, C., Iglesias, M., y Lozano, C. (2016). El trabajo colaborativo en la Educación Superior: una competencia profesional para los futuros docentes. Educ. Soc., Campinas, 37(135), 519-538. https://doi.org/10.1590/ES0101-73302016147914 
García, F. J. P., y Peláez, A. L. (2017). La intensificación del trabajo en España (2007-2011): trabajo en equipo y flexibilidad. Reis: Revista española de investigaciones sociológicas, (160), 79-94. http://dx.doi.org/10.5477/cis/reis.160.79

Gasca, H. G. P., Peña, A., Gómez, Á. M. C., Plascencia, O. Ó. A., \& Calvo, M. J. A. (2015). Realidad virtual como buena práctica para trabajo en equipo con estudiantes de ingeniería. RISTI-Revista Ibérica de Sistemas e Tecnologias de Informação, (16), 76-91. http://dx.doi.org/10.17013/risti.16.76-91

Gillies, R. (2014). Developments in cooperative learning: Review of research. Anales de Psicología, 30(3), 792-801. https://doi.org/10.6018/analesps.30.3.201191

González, J., Tejedor, F. N., \& Pinzón, R. (2019). A Bibliographic Review of the Importance of Carbon Dioxide Capture in Mangroves. Electrical and Electronics Engineers, (1), 126-131. http://dx.doi.org/10.1109/IESTEC46403.2019.00-89

Herrera, R. F., Muñoz, F. C., y Salazar, L. A. (2017). Diagnóstico del trabajo en equipo en estudiantes de ingeniería en Chile. Formación universitaria, 10(5), 49-58. https://doi.org/10.4067/S0718-50062017000500006

Hidayati, N., \& Etikariena, A. (2018). Gaining engaged people to succeed Sustainable Development Goals (SDGs). E3S Web of Conferences, (74), 1-6. https://doi.org/10.1051/e3sconf/20187408017

Hurtado, M. D., y Lara, L. Á. (2015). Efectividad del aprendizaje cooperativo en contabilidad: una contrastación empírica. Revista de Contabilidad, 18(2), 138-147. https://doi.org/10.1016/j.rcsar.2014.05.003

Jaime, V. R. V., \& Lizcano, D. A. R. (2015). ICT mediated collaborative work in system $\begin{array}{llll}\text { dynamics } \quad \text { learning. } & \text { 82(189), }\end{array}$ https://doi.org/10.15446/dyna.v82n189.42026

Järvelä, S. (2015). El papel de la investigación sobre aprendizaje autorregulado en el desarrollo del aprendizaje colaborativo asistido por ordenador. Infancia $y$ Aprendizaje, 38(2), 279-294. https://doi.org/10.1080/02103702.2015.1016747

Koh, Y. G., y Castillo, L. T. (2014). Trabajo colaborativo con mujeres: Una experiencia en clínica comunitaria. Psicoperspectivas, 13(2), 121-132. https://doi.org/10.5027/psicoperspectivas-Vol13-Issue2-fulltext-356

Lata, D., y Castro, R. (2016). El aprendizaje cooperativo un camino hacia la inclusión educativa. Revista Complutense de Educación, 27(3), 1085-1101. https://doi.org/10.5209/rev_RCED.2016.v27.n3.47441 
Lazzari, M. (2014). Combinación de Aprendizaje Cooperativo e Individual en una Asignatura de Química de Materiales. Formación universitaria, 7(4), 39-46. https://doi.org/10.4067/S0718-50062014000400005

León, B., Polo, M. I., Gozalo, D. M., y Mendo, L. S. (2016). Relevancia del aprendizaje cooperativo sobre los diferentes perfiles de la dinámica bullying: un análisis mediante pruebas de tamaño del efecto. Anales de psicología, 32(1), 80-88. https://doi.org/10.6018/analesps.32.1.183141

Lillo, E. J. S., Muñoz, M. P. B., \& Butter, M. C. (2020). Gestión del tiempo, trabajo colaborativo docente e inclusión educativa. Revista Colombiana de Educación, 1(78), 343-360. http://doi.org/10.17227/rce.num78-9526

López, D. L., Fleta, J. L., Sardaña, A. U., Torres, P. A., y García, C. B. (2017). Trabajo en equipo y estilos de aprendizaje en la educación superior. Revista Complutense de Educación, 28(4), 1267-1284. https://doi.org/10.5209/RCED.51722

López, G. K., y Molina, N. V. (2018). Incidencia del trabajo colaborativo docente en la enseñanza y el aprendizaje de la escritura académica. REDIE: Revista electrónica de investigación educativa, 20(1), 1-13. https://doi.org/10.24320/redie.2018.20.1.1477

Martín, S. C., y Cid, G. M. (2018). Experiencia de aprendizaje cooperativo en una asignatura optativa del Grado en Enfermería. Educación Médica, 19(5), 288-293. https://doi.org/10.1016/j.edumed.2017.10.035

Martínez, S. P., Gmelch, N., y Xarles, J. G. (2019). El plan de acción de conocimiento abierto de la UOC: La apuesta por un cambio cultural de la universidad. RUIDERAe: Revista de Unidades de Información, 1-14. https://ruidera.uclm.es/xmlui/handle/10578/22022

Mellado, H. M. E., Chaucono, C. J. C., Hueche, O. M. C., \& Aravena, K. O. A. (2017). Percepciones sobre la educación inclusiva del profesorado de una escuela con Programa de Integración Escolar. Revista Educación, 41(1), 119-132. http://dx.doi.org/10.15517/revedu.v41i1.21597

Montaño, M. J., Martínez, A. L., y Torre, M. E. (2017). El trabajo colaborativo en red impulsor del desarrollo profesional del profesorado. Revista Brasileira de Educação, 22(70), 651-667. https://doi.org/10.1590/s1413-24782017227033

Morales, M. L., García, M. O., Torres, R. A., y Lebrija, T. A. (2018). Habilidades Cognitivas a través de la Estrategia de Aprendizaje Cooperativo y Perfeccionamiento Epistemológico en Matemática de Estudiantes de Primer Año de Universidad. Formación Universitaria, 11(2), 45-56. https://doi.org/10.4067/S071850062018000200045 
Muñoz, R., y Tejedor, T. (2018). Valoración del trabajo colaborativo en los procesos de enseñanza-aprendizaje en entornos escolares con alto nivel TIC. Estudios sobre Educación, (34), 155-175. https://doi.org/10.15581/004.34.155-175

Orsini, C. A., Danús, M. T., y Tricio, J. A. (2019). La importancia de la educación interprofesional en la enseñanza de la odontología: una revisión sistemática exploratoria analizando el dónde, el porqué y el cómo. Educación Médica, 1-13. https://doi.org/10.1016/j.edumed.2018.04.016

Palomino, M. (2018). Formación en competencias en alumnado universitario de Educación Social mediante prácticas basadas en aprendizaje cooperativo. Revista Complutense de Educación, 29(3), 829-845. https://doi.org/10.5209/RCED.53970

Panitz, T. (2001). Distinction between definitions of collaborative and cooperative learning. Delaware: Swarthmore Editors.

Pérez, F. M., Sierra, A. B., y Quijano, L. R. (2018). Percepción y creencias del alumnado de primero de los títulos de grado de educación infantil y primaria, en jaén y oviedo, acerca de la competencia 'trabajo en equipo'. Profesorado. Revista de Currículum y $\begin{array}{llll}\text { Formación del } & \text { 9-29. }\end{array}$ https://doi.org/10.30827/profesorado.v22i3.7988

Poy, C. R., Mendaña, C. C., y González, B. (2015). Diseño y evaluación de un juego serio para la formación de estudiantes universitarios en habilidades de trabajo en equipo. RISTI-Revista Ibérica de Sistemas e Tecnologias de Informação, (3), 71-83. https://doi.org/10.17013/risti.e3.71-83

Quiñonez, Y., Luzardo, G., y Granda, R. (2016). Implementación de un sistema multi-táctil en ambientes educativos para promover y facilitar la evaluación del trabajo colaborativo en el aula. RISTI-Revista Ibérica de Sistemas e Tecnologias de Informação, (17), 66-79. http://dx.doi.org/10.17013/risti.17.66-79

Reyes, G. É., Fernández, P. F., Pérez, N. W., y Urrutia, U. P. (2018). Aplicación Sigma y Grupos Facebook: Evaluación de la Usabilidad y Aceptación Tecnológica por Estudiantes de Ingeniería de Sistemas de la Universidad Técnica de Ambato en Ecuador. Formación universitaria, 11(5), 65-74. https://doi.org/10.4067/S071850062018000500065

Rivarossa, J., y Bruccini, R. (2017). Sentidos y tensiones de los Talleres de Práctica Docente. Conexión. Revista de Investigaciones y Propuestas Educativas, (14), 52-61. http://iesoc.edu.ar/publicaciones/wp-content/uploads/sites/3/2017/12/RivarissaBruccini.pdf 
Robbins, H., \& Giaccardi, E. (2019). Generating value across academic and professional design practice in the Internet of Things. CoDesign, 1-17. https://doi.org/10.1080/15710882.2018.1563192

Ruíz, C. M., y de Rivas, M. R. (2015). Los valores vinculados a la competencia del trabajo en equipo en entornos virtuales de aprendizaje. Un estudio en la Universidad Técnica Particular de Loja (Ecuador). Revista Complutense de Educación, 26(3), 759-780. https://doi.org/10.5209/rev_RCED.2015.v26.n3.45682

Ruiz, M. (2014). La recreación del universo profesional en el aula a través de técnicas de aprendizaje colaborativo: el Método del Caso y el Juego de Rol1. Historia y Comunicación Social, (19), 223-234. https://doi.org/10.5209/rev_HICS.2014.v19.45023

Rus, T. I., Martínez, E. A., Frutos, A. E., y Moreno, J. R. (2019). El aprendizaje cooperativo en la formación de maestros de Educación Primaria. Revista de Investigación Educativa, 37(2), 543-559. http://dx.doi.org/10.6018/rie.37.2.369731

Sardi, S., Vardi, R., Goldental, A., Sheinin, A., Uzan, H., \& Kanter, I. (2018). Adaptive nodes enrich nonlinear cooperative learning beyond traditional adaptation by links. Scientific reports, 8(1), 1-10. https://doi.org/10.1038/s41598-018-23471-7

Sepúlveda, P. (2018). Percepción de los estudiantes de educación inicial frente al desarrollo de experiencias formativas en modalidad A+ S. REDIE: Revista Electrónica de Investigación Educativa, 20(4), 110-122. https://doi.org/10.24320/redie.2018.20.4.1826

Serrano, J. M., y Pons, R. M. (2014). Introducción: aprendizaje cooperativo. Anales de psicología, 30(3), 781-784. https://doi.org/10.6018/analesps.30.3.201251

Sharan, Y. (2014). Learning to cooperate for cooperative learning. Anales de Psicología, 30(3), 802-807. https://doi.org/10.6018/analesps.30.3.201211

Slavin, R. (2014). Cooperative learning and academic achievement: Why does groupwork work?. Anales de psicología, 30(3), 785-791. https://doi.org/10.6018/analesps.30.3.201201

Soria, I. N., Gómez, C. G., Monsalve, B. L., y Pérez, P. B. (2015). Aprendizaje de contenidos académicos y desarrollo de competencias profesionales a través de prácticas pedagógicas multidisciplinares y trabajo cooperativo. Revista de Investigación Educativa, 33(1), 99-117. https://doi.org/10.6018/rie.33.1.183971

Soto, A. (2011). Mitos y símbolos en la campaña de Barack Obama. Palabra clave, 14(1), 67-82. https://doi.org/10.5294/pacla.2011.14.1.4 
Trejos, B. O. (2019). Metodología de trabajo en grupo para aprender programación de computadores. Educación y Humanismo, 21(36), 23-39. https://doi.org/10.17081/eduhum.21.36.3002

Van der Hoek, M., Groeneveld, S., \& Kuipers, B. (2016). Goal Setting in Teams: Goal Clarity and Team Performance in the Public Sector. Review of Public Personnel Administration, 38(4), 472-493. https://doi.org/10.1177/0734371X16682815

Villamil, R. E. E. (2017). La comunicación interna como herramienta estratégica en la empresa: un análisis desde la gestión organizacional [Tesis de Especialización, Universidad Militar Nueva Granada]. https://repository.unimilitar.edu.co/handle/10654/16401

Were, V., Jere, E., Lanyo, K., Mburu, G., Kiriinya, R., Waudo, A., \& Rodgers, M. (2019). Success of a South-South collaboration on Human Resources Information Systems (HRIS) in health: a case of Kenya and Zambia HRIS collaboration. Human resources for health, 17(1), 1-8. https://doi.org/10.1186/s12960-019-0342-z

Yorg, J. A., \& Zarza, A. M. R. (2020). El derecho cooperativo y el docente cooperativo. International Association of Cooperative Law Journal, (56), 169-180. http://dx.doi.org/10.18543/baidc-56-2020pp169-180

Yusuf, Q., Jusoh, Z., \& Yusuf, Y. Q. (2019). Cooperative Learning Strategies to Enhance Writing Skills among Second Language Learners. International Journal of Instruction, 12(1), 1400-1412. https://doi.org/10.29333/iji.2019.12189a

Zárate, A. W. K. (2016). El esquema de roles en entornos de aprendizaje cooperativo [Tesis de Maestría, Pontificia Universidad Católica del Perú]. http://tesis.pucp.edu.pe/repositorio/handle/20.500.12404/9230 